\title{
Termos Mentais na Contação de Histórias e a Teoria da Mente das Crianças
}

\author{
Greicy Boness de Araujo ${ }^{1}$ \\ Tania Mara Sperb \\ Universidade Federal do Rio Grande do Sul \\ Hélio Radke Bittencourt \\ Pontifícia Universidade Católica do Rio Grande do Sul
}

\begin{abstract}
RESUMO - A literatura destaca a potencialidade das histórias para favorecer conversas sobre estados mentais, aspectos que contribuem para o desenvolvimento da teoria da mente. O objetivo deste estudo é verificar a relação entre a teoria da mente e o discurso narrativo de mães quanto ao emprego de termos mentais, no contexto da contação de histórias. A amostra foi constituída por 25 duplas de mães e crianças, de nível socioeconômico médio, tendo as crianças idades entre quatro e cinco anos. Os resultados mostraram que o emprego de cognições clarificadas pelas mães em suas narrativas apresenta relação significativa com a teoria da mente das crianças. A contação de histórias parece desempenhar um papel interessante na estimulação da conversação sobre termos mentais e, assim, no desenvolvimento sociocognitivo infantil.
\end{abstract}

Palavras-chave: teoria da mente, narrativa, termos mentais, cognições clarificadas

\section{Mental Terms in the Context of Telling Stories and Children's Theory of Mind}

\begin{abstract}
The literature highlights the potentiality of stories in favoring conversations about mental states, aspects that contribute to the development of a theory of mind. The aim of this study is to evince the relationship between a theory of mind and mothers' narrative discourse as regards to the use of mental terms in the context of telling stories. Twenty-five middleclass mothers and their four to five old children composed the dyads used as sample. Results showed that the mothers' use of clarifying cognitions in their narratives related significantly with the children's theory of mind. Telling stories seems to be an effective tool to stimulate the conversation about mental states, thereby resulting in the social cognitive development of children.
\end{abstract}

Keywords: theory of mind, narrative, mental terms, clarifying cognitions

O entendimento da relação entre o comportamento das pessoas e o que se passa em sua mente é uma importante habilidade sociocognitiva chamada teoria da mente, a qual se desenvolve a partir da interação e é considerada fundamental para o êxito nas relações sociais (Maluf \& Domingues, 2010). No campo da cognição humana, Piaget é um dos precursores no estudo da teoria da mente por já se interessar, no início do século XX, pelos conteúdos mentais infantis (Piaget, 1923/1961). Um dos primeiros usos do termo teoria da mente ocorreu quando primatologistas investigavam se os chimpanzés possuíam a habilidade de atribuir estados mentais a outros chimpanzés. Através das pesquisas desenvolvidas, estes pesquisadores concluíram que o sucesso dos chimpanzés nas tarefas às quais foram submetidos indicava que eles possuíam uma teoria da mente (Baron-Cohen, Tager-Flusberg, \& Cohen, 1994; Premack \& Woodruff, 1978).

A avaliação da habilidade de teoria da mente tem se centrado historicamente na investigação da capacidade de atribuição de crença falsa. As tarefas de crença falsa, elaboradas inicialmente por Wimmer e Perner (1983), avaliam a capacidade da criança de compreender que uma

1 Endereço para correspondência: Av. Pirapó 206/202, Bairro Petrópolis, Porto Alegre, RS, Brasil. CEP. 90470-450.E-mail: greboness@hotmail. com. pessoa pode ter uma crença falsa, que não condiz com a realidade, e que esta influenciará seu comportamento, o que seria sinal de aquisição da teoria da mente.

A relação entre teoria da mente e linguagem é uma questão bastante aceita pelos pesquisadores do campo de estudos da sociocognição (Gallo-Pena \& Maluf, 2013; Maluf \& Domingues, 2010; Maluf \& Gallo-Pena, 2011; Rodrigues, Pelisson, Silveira, Ribeiro, \& Silva, 2015; Rodrigues \& Pires, 2010). Ao associar-se a linguagem e a interação social, o discurso parental, que envolve as conversas sobre pensamentos, desejos e sentimentos, surge como fator preponderante para que a criança desenvolva o entendimento social e a teoria da mente.

Estudos precursores de tipo longitudinal, como de Dunn, Brown e Beardsall (1991), constataram a importância do discurso familiar para o entendimento das emoções de crianças pequenas. As pesquisadoras verificaram que o uso que pais e mães fazem da linguagem que envolve sentimentos e emoções prediz o reconhecimento das emoções pela criança e a sua capacidade de compreensão emocional, três anos mais tarde. Já Ruffman, Slade e Crowe (2002) verificaram que a linguagem de estados mentais usada com as crianças pequenas prediz o sucesso destas em tarefas que avaliam a teoria da mente mais adiante.

Entre as trocas linguísticas, a atividade de contação de histórias é uma forma comum de discurso familiar entre pais e filhos que oportuniza descrever eventos e fazer reflexões 
sobre a história, sobre os pensamentos e os sentimentos dos personagens. Esse hábito, conforme Rodrigues e Pires (2010), permitiria não apenas a apropriação de termos mentais, mas o desenvolvimento da teoria da mente.

Segundo Bruner (1991), as histórias constituem-se em uma fonte valiosa de dados para a compreensão da mente porque elas não são independentes do que se passa na mente de quem delas participa. $\mathrm{O}$ autor afirma que as histórias e narrativas apresentam um duplo cenário: um de ação, que é organizado em torno de um tema, com a emergência de um problema; e um cenário de consciência, o qual abarca os objetivos, as motivações, emoções e crenças dos atores que realizam a ação. Os dois cenários favorecem o contato da criança com a linguagem mental e com a possibilidade de relacionar as ações dos personagens com suas intenções, motivações e sentimentos. As narrativas e histórias, portanto, desempenham um importante papel no desenvolvimento sociocognitivo, pois através delas as crianças desenvolvem a linguagem, ampliam seu pensamento e a capacidade de compreensão do mundo, avançando na habilidade de relacionar estados mentais com o comportamento das pessoas.

Ao contar histórias, Nelson (2005) observa que os pais costumam incluir diferentes fontes de conhecimento, a reflexão sobre experiências próprias e dos outros, ou ainda, a distinção entre acontecimentos reais e imaginários. Embora as crianças contribuam com poucas palavras, como ouvintes elas já estão ingressando nas práticas de escuta, atenção e interpretação da fala, formas de usar a linguagem como um meio de representação. As narrativas expressam desejos, intenções e pensamentos das pessoas em relação ao que fazem e também os estados emocionais em resposta aos resultados de suas ações. Ouvir histórias, portanto, é um importante ato de passagem ao longo do caminho para a comunidade de mentes, metáfora utilizada por Nelson (2005) para explicar o ingresso da criança no mundo social e cultural.

Um expressivo número de pesquisas mostra que é preferencialmente o discurso sobre estados mentais nas narrativas das mães que apresenta correlações positivas com o desempenho das crianças em tarefas de crença falsa (Dunn,1991; Maluf \& Domingues, 2010; Slaughter, Peterson, \& Mackintosh, 2007; Rodrigues \& Pires, 2010; Symons, Peterson, Slaughter, Roche \& Doyle, 2005; Taumoepeau \& Ruffman, 2006). Essas pesquisas avaliam a atividade de contação de histórias das mães, uma vez que esta é considerada uma situação interessante para a alusão aos estados mentais. Na maior parte desses estudos, as mães são convidadas a contar aos filhos histórias de livros de gravuras, sem texto. As histórias das mães são, então, analisadas quanto aos termos de estados mentais presentes, sejam cognitivos, emocionais ou perceptivos, e esses índices são correlacionados com o desempenho dos filhos nas tarefas que avaliam a teoria da mente. A ideia presente nesses trabalhos é a de que a referência aos estados mentais e a explicação destes pode afetar o entendimento que as crianças têm da mente.

Seguindo esta linha, Symons et al. (2005) encontraram que comentários específicos realizados acerca dos estados mentais dos personagens da história pelas mães relacionaramse positivamente com o desempenho das crianças em tarefas que examinam teoria da mente. Adrian, Clemente e Villanueva
(2007), por sua vez, investigaram, em atividades de contação de história, o uso de verbos cognitivos pelas mães, como saber e pensar, e a sua relação com o entendimento da mente pela criança. Os resultados indicaram que o emprego precoce desses verbos cognitivos pela mãe, ao contar histórias ao filho, correlacionou-se positivamente com o posterior entendimento deste dos estados mentais. Também Slaughter et al. (2007) encontraram, entre os resultados de seu estudo, que o desempenho das crianças em tarefas de teoria da mente correlacionou-se positivamente com o discurso materno sobre cognição, quando este envolveu o uso de explicações, causalidades e contrastes e não apenas a simples menção aos termos cognitivos. Os estudos descritos, portanto, utilizam as histórias como forma de acesso à influência linguística materna e afirmam a potencialidade das narrativas maternas no desenvolvimento sociocognitivo infantil.

Tendo em vista os resultados dessas investigações, aliado à carência de investigações brasileiras com esse enfoque, $\mathrm{o}$ presente estudo teve por objetivo verificar a relação existente entre o uso de termos mentais nas narrativas das mães em atividades de contação de histórias e o desempenho das crianças em tarefas que avaliam a teoria da mente.

\section{Método}

\section{Participantes}

Participaram deste estudo 25 duplas de mães e crianças, com idades entre quatro e cinco anos $(M=54,12$ meses, $\mathrm{DP}=4,94)$, sendo 12 meninos e 13 meninas, alunos de uma escola da rede privada de Porto Alegre, todos de nível socioeconômico médio, segundo a classificação de Hollingshead (1975).

\section{Instrumentos e Materiais}

Livros de histórias infantis sem texto. As narrativas foram coletadas em três sessões de contação de histórias, utilizando-se em cada sessão um livro diferente, sem texto, somente com imagens. Na primeira e na segunda sessão ,foram utilizados, respectivamente, os livros "O aniversário de Carlos" (Day, 1995) e "Carlos, o bom cachorro" (Day, 1997), já usados em pesquisas anteriores estrangeiras sobre teoria da mente. O livro "O aniversário de Carlos" apresenta como enredo a preparação de uma festa surpresa para o cachorro da família que acaba sendo descoberta pelo bebê e pelo próprio cachorro. Já o livro utilizado na segunda sessão retrata uma situação na qual a mãe sai de casa e deixa o bebê sob os cuidados do cachorro. Na terceira sessão foi utilizado o livro "Truks" (Furnari, 1998), de uma autora brasileira, escolhido a partir de um estudo piloto realizado com crianças da mesma faixa etária. O livro foi escolhido, entre outros da mesma autora, por suscitar maior alusão aos termos de estados mentais e apresenta a história de uma bruxa que faz magias e transforma os animais à sua volta de forma atrapalhada. 
Escala de tarefas em teoria da mente. As crianças responderam às seis primeiras tarefas de uma escala de tarefas de teoria da mente (cf. tradução de Domingues, Valério, Pancieira, \& Maluf, 2007), as quais apresentam, sinteticamente, o seguinte conteúdo (uma descrição detalhada das tarefas poderá ser obtida do primeiro autor):

Tarefa 1: reconhecimento de que as pessoas apresentam desejos diferentes acerca da mesma situação.

Tarefa 2: reconhecimento de que as pessoas possuem diferentes crenças sobre o mesmo objeto.

Tarefa 3: reconhecimento de que pessoas que não têm acesso a determinada informação, possuem uma idéia ou pensamento diferente daqueles que tiveram acesso à informação.

Tarefa 4: a criança avalia a crença falsa de outra pessoa sobre conteúdo de um recipiente característico, quando a criança já conhece o conteúdo do recipiente.

Tarefa 5: esta é a tarefa clássica que avalia a crença falsa. A criança deve avaliar onde determinado personagem irá procurar um objeto, sendo que o personagem apresenta ma crença equivocada sobre o local no qual está inserido o objeto.

Tarefa 6: a criança deve avaliar como uma pessoa se sente diante de uma crença equivocada.

Materiais lúdicos e gráficos. Foram utilizados bonecos, desenhos e também outros objetos necessários para a realização de cada tarefa de teoria da mente.

Questionário de dados sociodemográficos. $O$ instrumento foi empregado para a caracterização do contexto familiar.

\section{Delineamento e Procedimentos de Coleta de Dados}

Utilizou-se um delineamento longitudinal para avaliar a associação entre as variáveis do estudo: uso de termos de estados mentais nas narrativas maternas e desempenho das crianças na escala de tarefas de teoria da mente.

Os participantes foram selecionados através do procedimento de amostragem por conveniência (Salkind, 1997) sendo que, após a aceitação da pesquisa, por parte da escola, a pesquisadora participou das reuniões de pais da faixa etária escolhida para explicar a pesquisa e convidá-los a fazer parte do estudo. Com as famílias que aceitaram participar da pesquisa, foi agendada a data para a realização das atividades.

As sessões de contação de histórias aconteceram com um intervalo de cerca de três semanas, no ambiente escolar, em espaço reservado, sem a presença da pesquisadora e foram integralmente filmadas. As mães foram convidadas a contar aos filhos a história do livro específico de cada sessão, orientadas a narrar do jeito como quisessem e da forma mais natural possível, como se estivessem em casa. A primeira sessão teve ainda a finalidade de conversar sobre a pesquisa e preencher o instrumento de dados sociodemográficos.

A escala de tarefas de teoria da mente foi aplicada às crianças durante o horário de aula, em salas reservadas, com a utilização do material lúdico pertinente. Para familiarização e formação de vínculo com as crianças, a pesquisadora participou de atividades de inserção na rotina escolar antes do início da coleta de dados, durante o período de duas semanas.

O estudo foi aprovado pelo Comitê de Ética do Instituto de Psicologia da Universidade Federal do Rio Grande do Sul, sob o $\mathrm{n}^{\mathrm{o}}$ de protocolo 2008/091 e todas as mães participantes concordaram com o estudo e assinaram o termo de consentimento livre e esclarecido no primeiro encontro com a pesquisadora.

\section{Análise dos Dados}

As filmagens das três sessões de contação de histórias das 25 duplas de mães e crianças foram transcritas na íntegra, perfazendo um total de 75 narrativas. Cada uma das narrativas foi analisada de acordo com a ocorrência dos itens especificados abaixo.

Para o cálculo da fidedignidade, dois juízes classificaram, separadamente, $20 \%$ das narrativas das mães quanto à referência aos termos mentais gerais e aos tipos de termos mentais empregados (cf. explicitado abaixo). Os juízes classificaram os termos, separadamente, e suas classificações foram comparadas à da pesquisadora para o cálculo da fidedignidade. Eventuais diferenças entre eles foram resolvidas por consenso. O índice utilizado entre os juízes foi calculado utilizando-se o ICC (Coeficiente de Correlação Intraclasses), que gerou um índice classificatório para cada um dos termos mentais.

\section{Narrativas das Mães}

As histórias das mães foram analisadas quanto ao número total de termos de estados mentais (referência a sentimentos, percepções e sentimentos), número total de termos de estados comportamentais (referência a ações) e número total de termos de estados físicos (referência a aspectos físicos da história) de acordo com Symon et al. (2005).

Os termos de estados mentais foram classificados também em critérios específicos. Foram extraídas todas as falas que incluem conteúdos mentais, as quais foram classificadas e quantificadas em relação à frequência dos critérios abaixo (cf. Slaugther et al., 2007):

\section{Tarefas de Teoria da Mente das Crianças}

Após a aplicação das tarefas, as quais contêm duas questões cada, as respostas foram analisadas. Para a resposta ser considerada correta, a criança deve responder corretamente as duas questões. A resposta correta corresponde a 1 ponto e a resposta incorreta corresponde a 0. Foram utilizados dois indicadores nessa escala: na tarefa 5 , que corresponde à clássica tarefa de crença falsa, a presença ou ausência de acertos serviu como indicador da habilidade da criança de atribuir crença falsa ao outro; o outro indicador utilizado foi o número total de acertos obtidos pela criança, considerando todas as seis tarefas, que pode variar de 0 a 6 . 
Tabela 5. Classificação quanto aos tipos de estados mentais (adaptado de Slaughter et al, 2007)

\begin{tabular}{ll}
\hline \multicolumn{1}{c}{ Termos mentais } & \multicolumn{1}{c}{ Definições } \\
\hline Cognições simples & $\begin{array}{l}\text { Nomes, verbos ou adjetivos simplesmente descrevendo } \\
\text { atos mentais de pensamento ou raciocínio, sem a } \\
\text { elaboração sobre os conteúdos ou causas para aqueles } \\
\text { estados mentais. Ex: ele pensou. }\end{array}$ \\
& $\begin{array}{l}\text { Frases ou sentenças esclarecendo estados mentais } \\
\text { cognitivos. Ex: ela não viu o jogo, assim ela não saberá } \\
\text { quem ganhou. }\end{array}$ \\
& Nomes, verbos ou adjetivos simplesmente nomeando \\
Afeto simples & sentimentos, emoções, desejos, intenções, sem explicar \\
& a respeito destes. Ex: o bebê está feliz. \\
Afeto clarificado & Frases ou sentenças clarificando estados afetivos. Ex: \\
ele está feliz que mamãe está finalmente em casa. & Frases ou sentenças descrevendo estados ou processos \\
Percepção simples & relativos à percepção ou atenção. Ex: Ele viu pela \\
& janela. \\
Percepção clarificada & $\begin{array}{l}\text { Frases ou sentenças clarificando estados de atenção ou } \\
\text { percepção. Ex: Olhou pela janela para ver a mamãe }\end{array}$ \\
Somatório Termos Mentais & Somatório dos termos mentais de todas as três histórias. \\
\hline
\end{tabular}

\section{Tratamento estatístico}

Foram utilizadas técnicas estatísticas descritivas e inferenciais. A parte descritiva consistiu de tabelas de freqüência simples e medidas descritivas convencionais. $\mathrm{Na}$ parte inferencial, o tipo de técnicas variou conforme as variáveis selecionadas. O coeficiente de correlação de Pearson foi utilizado para mensurar o grau de associação entre as variáveis das narrativas das mães (termos mentais gerais, termos comportamentais e físicos, bem como os tipos de termos de estados mentais) e os indicadores de teoria da mente da criança (escore na escala de tarefas de teoria da mente e escore na tarefa de crença falsa). O teste $t$ de Student foi utilizado para comparações entre crianças com ou sem pontuação na tarefa de crença falsa. Análises de regressão linear procuraram identificar relações de predição e de explicação entre as variáveis da narrativa da mãe e a teoria mente da criança.

\section{Resultados}

Os resultados são apresentados em três partes, com foco nos principais achados obtidos. Os termos mentais totais e os tipos específicos de termos mentais (cognições, afetos e percepções) compuseram cada um deles um só escore que foi composto pela soma de todos estes indicadores empregados pelas mães em suas narrativas nas três sessões de histórias.

\section{A Análise Descritiva das Variáveis: Termos Mentais das Mães e Teoria da Mente das Crianças}

A tabela 1 mostra a frequência média e o desvio padrão de termos mentais, comportamentais e físicos encontrados nas narrativas das mães, nas três histórias utilizadas no estudo. A tabela mostra ainda a frequência média e desvio padrão dos tipos de termos de estados mentais empregados pelas mães nas três sessões de histórias e a média e desvio padrão dos totais de termos clarificados e dos totais de termos simples.

Os dados mostram uma grande variabilidade na utilização de termos mentais, comportamentais e físicos pelas mães, durante as histórias, assim como na atribuição de diferentes tipos de estados mentais aos personagens da história. O desvio padrão elevado evidencia esta variabilidade. As cognições clarificadas $(M=13,80)$, seguidas pelos afetos clarificados $(M=13,16)$ e pelas percepções simples $(M=11,48)$ são os tipos de termos mentais mais empregados pelas mães. Notase ainda que a utilização de explicações pelas mães (termos clarificados) apresenta uma média mais elevada $(M=33,56)$

Tabela 1. Estatísticas descritivas das ocorrências para as variáveis das narrativas maternas $(n=25)$

\begin{tabular}{lcc}
\hline Variáveis & Média & DP \\
\hline Total de Termos mentais & 54,24 & 15,12 \\
Total de Termos comportamentais & 88,84 & 30,77 \\
Total de Termos físicos & 44,32 & 25,56 \\
Cognições simples & 1,96 & 1,65 \\
Cognições clarificadas & 13,80 & 7,27 \\
Afeto simples & 6,92 & 4,22 \\
Afeto clarificado & 13,16 & 5,01 \\
Percepção simples & 11,48 & 4,21 \\
Percepção clarificada & 6,60 & 3,16 \\
Crença falsa final & 1,00 & 0,76 \\
Total de termos mentais simples & 20,36 & 6,72 \\
Total de termos clarificados & 33,56 & 11,65 \\
\hline
\end{tabular}


do que a simples menção $(M=20,36)$ aos diferentes tipos de termos mentais (termos simples).

No que concerne ao desempenho das crianças na escala de tarefas de teoria da mente, os resultados mostraram as seguintes freqüências: sete crianças acertaram seis tarefas da escala (28\%); sete crianças acertaram cinco tarefas da escala (28\%); quatro crianças obtiveram escores de quatro tarefas $(16 \%)$; quatro crianças obtiveram três acertos na escala (16\%); uma criança acertou duas tarefas (4\%); uma criança acertou uma tarefa $(4 \%)$ e apenas uma criança obteve escore zero (4\%).

Quanto à frequência de acertos na tarefa específica que avalia a crença falsa, do total de 25 crianças participantes deste estudo, verificou-se que 11 crianças (44\%) não obtiveram êxito na tarefa e que 14 crianças $(56 \%)$ acertaram a tarefa específica da crença falsa.

\section{As Histórias das Mães e a Teoria da Mente das Crianças na Escala de Teoria da Mente: Correlações e Regressões}

A tabela 2 apresenta a correlação bivariada entre os escores das crianças na escala de tarefas de teoria da mente e o uso de termos de estados mentais nas narrativas das mães.

Tabela 2. Coeficientes de correlação de Pearson entre as variáveis da narrativa materna e o escore total das crianças na escala de tarefas de teoria da mente $(n=25)$

\begin{tabular}{lc}
\hline Escore teoria da mente crianças & $\begin{array}{c}\text { Escore teoria da } \\
\text { mente crianças }\end{array}$ \\
\hline T. mentais mãe & 1,000 \\
T. comportamentais mãe & 0,207 \\
T.físicos mãe & $-0,437(*)$ \\
Cognições simples mãe & $-0,523(* *)$ \\
Cognições clarificadas mãe & 0,097 \\
Afetos simples mãe & $0,495(*)$ \\
Afetos clarificados mãe & $-0,152$ \\
Percepções simples mãe & 0,160 \\
Percepções clarificadas mãe & $-0,023$ \\
Crença Falsa Final História Mãe & 0,137 \\
Notas. * Correlação significativa ao nível de significância de $5 \%(p<0,05)$ \\
$* *$ Correlação significativa ao nível de significância de $1 \%(p<0,01)$
\end{tabular}

Foram encontradas correlações significativas entre o escore total das crianças na escala de tarefas de teoria da mente e a frequência de uso de cognições clarificadas pelas mães. Além disso, o uso de termos físicos e de termos comportamentais pelas mães apresentou correlação significativa inversa com o desempenho da criança na escala de tarefas de teoria da mente: quanto mais frequente o uso de termos físicos e comportamentais pelas mães, menor o escore das crianças na escala de tarefas de teoria da mente. Ainda, a simples menção de termos cognitivos pelas mães não apresentou correlação significativa com o desempenho das crianças na escala; o mesmo ocorreu com relação ao uso de termos afetivos e perceptivos, simples ou clarificados/ explicados, e à presença da crença falsa da personagem mãe no final das histórias.

Para verificar relações de dependência e explicação entre as variáveis das mães e das crianças, foi realizada uma análise de Regressão Múltipla Stepwise. O objetivo foi verificar se as variáveis da narrativa materna (termos físicos, comportamentais e cognições clarificadas) que apresentaram correlação com o escore das crianças na escala de teoria da mente também seriam preditoras deste desempenho. A tabela

Tabela 3. Resumo da análise de regressão entre as variáveis da narrativa materna e o escore total das crianças na escala de tarefas de teoria da mente

\begin{tabular}{lcccc}
\hline Variável Preditora & $B e t a$ & $R$ & $R 2$ & $p$ \\
\hline Cognições Clarificadas Mãe & 0,469 & 0,702 & 0,493 & 0,005 \\
\hline Termos físicos Mãe & $-0,499$ & 0,523 & 0,273 & 0,003 \\
\hline
\end{tabular}

5 mostra o resumo do modelo de regressão realizado, tendo como variável dependente o escore das crianças na escala de tarefas de teoria da mente e como variáveis independentes as cognições clarificadas das mães e a frequência de emprego de termos físicos por elas nas histórias narradas.

De acordo com a análise empregada, o valor de $R(R=$ $0,702)$ mostra que a associação entre as variáveis é forte e que se pode explicar $49,3 \%\left(R^{2}=0,493\right)$ das variações no escore total da escala de TM das crianças pela frequência de uso de termos mentais cognitivos clarificados pela mãe. Por outro lado, a diminuição da frequência de termos físicos pelas mães também apresenta associação com o escore das crianças na escala de teoria da mente $(R=0,523)$, mas explica apenas $27 \%$ das variações deste escore $\left(R^{2}=0,273\right)$. O modelo e os coeficientes foram significativos ao nível de $1 \%(p<0,01)$.

\section{A Análise das Histórias das Mães e o Desempenho das Crianças na Tarefa de Crença Falsa}

A tabela 4 mostra a comparação das médias de variáveis da narrativa materna entre os grupos de crianças que tiveram presença ou ausência de pontuação na tarefa de crença falsa.

Os resultados indicam que houve diferença significativa entre o grupo das crianças que acertaram a tarefa que avalia a crença falsa e a frequência de utilização de termos mentais, de cognições clarificadas e de afetos clarificados pelas mães. Comparativamente, no grupo que não acertou a tarefa, as mães empregaram estes termos com menor frequência em suas narrativas. Além disso, o uso de cognições simples, afetos simples e percepções não se diferenciou entre os dois grupos avaliados.

\section{Discussão}

O presente estudo propôs-se a verificar a relação existente entre o uso de termos mentais nas narrativas maternas, em atividades de contação de histórias, e a teoria da mente da criança por meio de duas variáveis: o escore na escala de tarefas de teoria da mente e o escore em uma tarefa específica de crença falsa. 
Tabela 4. Teste t de Student para comparação das médias das variáveis da narrativa materna de acordo com a presença ou ausência de pontuação na tarefa de crença falsa $(n=25)$

\begin{tabular}{|c|c|c|c|c|c|}
\hline Variáveis & $\mathbf{N}$ & $\begin{array}{c}\text { Crença } \\
\text { falsa }\end{array}$ & Média & DP & $\begin{array}{l}\text { Valor } \\
\text { de p }\end{array}$ \\
\hline \multirow[t]{2}{*}{ Termos mentais } & 11 & Não & 47,730 & 11,680 & $0,046^{*}$ \\
\hline & 14 & Sim & 59,360 & 15,911 & \\
\hline \multirow{2}{*}{$\begin{array}{l}\text { Cognições } \\
\text { simples }\end{array}$} & 11 & Não & 1,910 & 1,221 & 0,894 \\
\hline & 14 & Sim & 2,000 & 1,961 & \\
\hline \multirow{2}{*}{$\begin{array}{l}\text { Cognições } \\
\text { clarificadas }\end{array}$} & 11 & Não & 9,000 & 4,405 & $0,002 * *$ \\
\hline & 14 & Sim & 17,570 & 6,914 & \\
\hline \multirow[t]{2}{*}{ Afetos simples } & 11 & Não & 7,090 & 4,482 & 0,862 \\
\hline & 14 & Sim & 6,790 & 4,173 & \\
\hline \multirow{2}{*}{$\begin{array}{l}\text { Afetos } \\
\text { clarificados }\end{array}$} & 11 & Não & 10,910 & 2,625 & $0,044 *$ \\
\hline & 14 & Sim & 14,930 & 5,784 & \\
\hline \multirow{2}{*}{$\begin{array}{l}\text { Percepções } \\
\text { simples }\end{array}$} & 11 & Não & 12,090 & 4,415 & 0,532 \\
\hline & 14 & Sim & 11,000 & 4,151 & \\
\hline \multirow{2}{*}{$\begin{array}{l}\text { Percepções } \\
\text { clarificadas }\end{array}$} & 11 & Não & 5,450 & 2,339 & 0,110 \\
\hline & 14 & $\operatorname{Sim}$ & 7,500 & 3,503 & \\
\hline \multirow[t]{2}{*}{ Crença falsa final } & 11 & Não & 1,090 & 0,831 & 0,608 \\
\hline & 14 & Sim & 0,930 & 0,730 & \\
\hline
\end{tabular}

Notas. * Diferença significativa entre médias ao nível de $5 \%(p<0,05)$

** Diferença significativa entre médias ao nível de $1 \%(p<0,01)$

Os resultados do presente estudo mostraram que as mães das crianças pré-escolares diferenciaram-se na frequência com que utilizaram os termos mentais em suas histórias, no tipo de termos utilizados e no emprego de clarificações ou explicações a respeito destes. Elas utilizaram uma variedade de termos mentais em suas histórias, tanto cognitivos, como afetivos ou perceptivos. A literatura da área (Adrian et al., 2007; Domingues \& Maluf, 2013; Maluf \& Domingues, 2010; Rodrigues \& Pires, 2010; Slaughter et al., 2007; Taumoepeau \& Ruffman, 2006) tem afirmado esta variabilidade no discurso materno quanto à referência aos estados mentais, indicando que quanto mais frequente é o emprego dos termos mentais por parte dos membros da família, especialmente das mães, mais avançada é a teoria da mente das crianças.

\section{A Relação entre o Emprego de Termos Mentais pelas Mães e a Teoria da Mente das Crianças}

Os resultados do presente estudo mostram que as variações no discurso narrativo das mães quanto à utilização dos diferentes tipos de termos mentais (cognitivos e afetivos) estão associadas a diferenças individuais na aquisição da teoria da mente das crianças. Os resultados das análises mostram correlações significativas e positivas entre os termos mentais empregados pelas mães, que no caso são os termos cognitivos clarificados, e as duas medidas de teoria da mente das crianças, o escore total da escala de tarefas de teoria da mente e a tarefa específica de crença falsa. As crianças cujas mães apresentaram frequência mais elevada de utilização dos termos mentais cognitivos clarificados demonstraram melhor desempenho na escala de tarefas de teoria da mente e, ainda, na tarefa específica que avalia a crença falsa.

Adrian et al. (2007) investigaram o emprego específico de verbos cognitivos pelas mães durante uma atividade de leitura compartilhada de história com seus filhos, em dois momentos distintos, com intervalo de um ano entre eles. Eles encontraram correlações positivas entre o entendimento de estados mentais pelas crianças e o uso de verbos cognitivos pelas mães, nos dois tempos do estudo. Além disso, os dados forneceram evidências longitudinais para supor que o uso de verbos cognitivos pelas mães, em idades precoces, constituise em um fator crítico para o desenvolvimento posterior da teoria da mente das crianças. Outras investigações referendam esse resultado, isto é, de que são as cognições, mais do que outros termos mentais que auxiliam as crianças no desenvolvimento e no avanço da teoria da mente (Adrian et al., 2007; Slaughter et al., 2007; Symons et al.,2005).

Entre os termos mentais, as cognições clarificadas mostraram-se ainda, no presente estudo, como o fator preditivo para o desempenho positivo na escala de tarefas de teoria da mente, que inclui a tarefa de crença falsa, como assinalado na análise de regressão efetuada. Elas explicam grande parte da variabilidade no desempenho da teoria da mente das crianças. O mesmo ocorreu na pesquisa de Slaughter et al. (2007), cujos resultados mostraram correlações estatísticas significativas entre os escores de crença falsa das crianças e o uso frequente de cognições clarificadas nas histórias contadas por suas mães. Também no estudo referido, além da correlação entre as variáveis, as cognições clarificadas no discurso da mãe contribuíram significativamente para explicar a variabilidade na teoria da mente das crianças.

Além da associação entre os termos mentais cognitivos empregados pelas mães e o desempenho das crianças na escala de teoria da mente e na tarefa de crença falsa, os resultados do presente estudo também indicaram correlações entre o uso de termos mentais gerais e os termos mentais afetivos ${ }^{1}$ clarificados das mães e o desempenho das crianças na tarefa específica que avalia a crença falsa. Isto é, o grupo de crianças que apresentou respostas corretas nessa tarefa teve também uma frequência mais alta de afetos clarificados nas narrativas maternas, além das cognições clarificadas. A esse respeito, apesar da importância das cognições nos resultados de um número expressivo de pesquisas, incluindo esta, há outros estudos que sugerem que o discurso dos pais com emprego frequente de uma variada amplitude de termos mentais, incluindo as emoções e desejos, além das crenças, contribuiria não somente para o sucesso das crianças na tarefa de crença falsa, mas também para o êxito em tarefas que avaliam o entendimento da emoção e de outros termos mentais (Adrian et al., 2007; Domingues \& Maluf, 2013, Dunn, Brown, \& Beardsall, 1991; Taumoepeau \& Ruffman,

1 Na classificação dos tipos de termos mentais utilizada no presente trabalho (Slaughter et al, 2007), os autores empregam o termo afetivo para designar emoções, sentimentos, desejos e intenções. 
2006). Rosnay, Pons, Harris e Morrel (2004) ratificam essa afirmação ao pontuarem que existe uma relação difusa e compartilhada entre os diversos termos mentais do discurso materno e o entendimento emocional e cognitivo das crianças. Para esse autor, esses dois campos não se constituem em domínios específicos, ou seja, não é o discurso sobre emoção que promoveria o entendimento da emoção e o discurso cognitivo que levaria ao entendimento cognitivo. Ambos estão articulados e se influenciam mutuamente. Essa posição de cautela com relação à separação entre cognição e emoção é feita por Souza (2008), ao reproduzir as palavras de Astington (2003, p. 34): "compreender estados cognitivos, como perceber que alguém é ignorante ou está enganado, é insuficiente para determinar como se comportar diante da pessoa. É preciso compreender também como eles se sentem em relação à situação".

Os resultados do presente estudo reforçam a posição dos autores citados no que concerne ao papel dos dois tipos de termos mentais, cognitivos e afetivos, já que ambos os termos, seguidos de clarificações, se associaram à teoria da mente das crianças (tarefa de crença falsa e escala de tarefas). Assim como neste estudo, a literatura da área dá importância às clarificações, ao sugerir que a tendência a explicitar os termos mentais, seja estabelecendo relações de causalidade ou contrastando diferenças entre as pessoas e/ ou a realidade, estaria mais associada ao desenvolvimento da teoria da mente do que a simples menção a eles (Gallo-Pena \& Maluf, 2013; Slaugther et al., 2007; Ruffman et al., 2002). Dunn (1996), na década de noventa, já havia encontrado que o uso de expressões cognitivas com explícita diferenciação entre estados mentais das pessoas, ou entre estados mentais e realidade correlacionou-se com o escore de crença falsa das crianças. Ruffman et al. (2002) sugeriu também que conversas entre pais e filhos, ricas em explicações causais para os estados mentais, estariam intimamente relacionadas com a compreensão da teoria da mente das crianças.

Os resultados encontrados por Slaughter et al. (2007), similares aos previamente citados e a este, referentes às associações entre teoria da mente e uso de explicações para os estados mentais dos personagens, presentes nas interações linguísticas entre mães e crianças, mostram que as explicações ampliam a percepção da criança sobre diferentes perspectivas e pontos de vista, favorecendo o desenvolvimento sociocognitivo e da teoria da mente. Nas opiniões de Slaughter et al. (2007), Nelson (2006) e Astington (2001), é difícil para as crianças compreenderem pensamentos que são discrepantes da realidade ou diferentes entre as pessoas, a menos que isso seja clarificado pelos pares, ao direcionarem sua atenção para estas questões e para o entendimento dos estados cognitivos que não são observáveis diretamente. Por meio das clarificações/explicações, os pais podem favorecer estas compreensões, explicando como os estados mentais relacionam-se ao comportamento, o que forneceria, portanto, suporte para a construção de uma teoria da mente.

Por fim, o fato de que as cognições clarificadas foram os termos mais empregados pelas mães nas histórias narradas aos filhos é consistente com o desenvolvimento do entendimento da mente pelas crianças nesta faixa etária. Como afirmam os pesquisadores (Deleau, Maluf, \& Panciera, 2008; Lyra, Roazzi, \& Garvey, 2008; Panciera, 2007; Roazzi \& Santana, 1999; Rodrigues, Pelisson, Silveira, Ribeiro, \& Silva, 2015; Wimmer \& Perner, 1983), é em torno dos quatro e cinco anos que as crianças são capazes de compreender que as pessoas possuem diferentes pensamentos, crenças ou idéias sobre os fatos e que estes aspectos governam seus comportamentos. As mães parecem tender a ajustar seu vocabulário à habilidade de entendimento das crianças, o que também já foi assinalado por estudos anteriores (Adrian et al., 2007; Gallo-Pena \& Maluf, 2013; Taumoepeau \& Ruffman, 2006). Essas ponderações também podem explicar o fato de que, neste estudo, foram encontradas correlações negativas entre o uso de termos físicos e comportamentais pelas mães em suas histórias e o desempenho das crianças em teoria da mente. Ou seja, quanto mais as mães empregaram este tipo de termo, menos as crianças tiveram êxito na tarefa de crença falsa. Isso mostra que as mães da presente pesquisa ajustaram-se às necessidades das crianças que, neste momento, parecem necessitar discutir estados mentais para avançarem em seu entendimento da teoria da mente.

\section{Conclusões}

Este estudo traz algumas contribuições. A primeira diz respeito ao importante papel desempenhado pelo emprego de termos mentais nas narrativas de mães para o desenvolvimento da teoria da mente das crianças. Os termos mentais gerais das mães se correlacionaram com a tarefa de crença falsa. Todavia, quanto aos tipos de termos mentais, são especificamente os termos mentais clarificados, tanto afetivos quanto cognitivos, que são os responsáveis pela correlação com a teoria da mente. Esse resultado também tem sido encontrado em estudos internacionais (Slaughter et al., 2007; Taumoepeau \& Ruffman, 2008) e em estudos brasileiros (Gallo-Pena \& Maluf, 2013) que observam que só a menção aos termos mentais não é suficiente para o avanço da teoria da mente das crianças, é importante que os termos sejam seguidos de explicação.

Em especial, destaca-se o emprego das cognições clarificadas para o desenvolvimento da teoria da mente das crianças. Esses resultados, que também aparecem na literatura internacional (Adrian et al., 2007; Slaughter et al., 2007; Tamoepeau \& Ruffman, 2008), fornecem subsídios para que se possa considerar a importância das cognições clarificadas nas histórias das mães como fator que pode favorecer e contribuir para a habilidade de compreensão dos estados mentais também em crianças brasileiras.

A contação de histórias pode ser considerada, de acordo com os resultados desta pesquisa, como uma ferramenta interessante para incentivar o desenvolvimento infantil da teoria da mente das crianças. Por ser um momento privilegiado para a discussão sobre termos mentais, a contação de histórias poderia ser estimulada nos principais contextos de educação infantil, como a família e a escola, a fim de favorecer o desenvolvimento sociocognitivo infantil. 
Em termos metodológicos, é importante ressaltar o acerto no emprego de três sessões de histórias, cada uma com um livro diferente, procedimento inovador, entre os trabalhos da área. As três sessões de histórias permitiram o surgimento de resultados interessantes, pois houve maior possibilidade das mães se expressarem e, deste modo, aportarem um número expressivo de estados mentais.

Uma limitação deste estudo a ser superada em pesquisas futuras é a ampliação do número de participantes e o emprego de medidas de controle relacionadas ao desenvolvimento linguístico das crianças. Com esse procedimento, poderse-ia averiguar como os aspectos linguísticos interferem no desempenho na escala de tarefas de teoria da mente.

\section{Referências}

Adrian, J., Clemente, A. \& Villanueva, L. (2007). Mothers' use of cognitive state verbs in picture-book reading and the development of children's understanding of mind: A longitudinal study. Child Development, 78(4), 1052-1067.

Baron-Cohen, S., Tager-Flusberg, H., \& Cohen, D. (1994). Understanding other minds: Perspectives from autism. New York: Oxford University Press.

Bruner, J. (1991). Realidade mental, mundos possiveis. Porto Alegre: Artes Médicas.

Day, A. (1995). Carl's Birthday. New York: Farrar Straus Giroux. Day, A. (1997). Good dog, Carl. New York: Aladdin Paperbacks.

Deleau, M., Maluf, M. R., \& Panciera, S. (2008). O papel da linguagem no desenvolvimento de uma teoria da mente: Como e quando as crianças se tornam capazes de representações de estados mentais. Em T. M. Sperb \& M. R. Maluf (Org), Desenvolvimento sociocognitivo: Estudos brasileiros sobre teoria da mente (pp. 93-130). São Paulo: Vetor.

Domingues, S., \& Maluf, M. R. (2013). Atribuição de estados mentais e linguagem: Um estudo de intervenção. Psicologia Escolar e Educacional, 17, 249-257.

Domingues, S. F. S., Valério, A., Panciera, S. P., \& Maluf, M. R. (2007). Tarefas de crença falsa na avaliação de atribuição de estados mentais de crença. Em P. W. Schelini (Org.), Alguns domínios da avaliação psicológica (pp. 141-162). Campinas, SP: Alínea.

Dunn, J., Brown, J., \& Beardsall, L. (1991). Family talk about feeling states and children's later understanding of other's emotion. Developmental Psychology, 27, 159- 164.

Dunn, J. (1991). The beginnings of social understanding. Oxford: Basil Blackwell.

Furnari, E. (1998). Truks. São Paulo: Ática.

Gallo-Penna, E., \& Maluf, M.R. (2013). Efeitos da linguagem materna na compreensão de estados mentais. Em A. Roazzi \& T.M. Sperb (Org), O desenvolvimento de competências sociocognitivas (pp. 121-142). São Paulo: Vetor.

Hollingshead, A. B. (1975). Four factor index of social status. Working paper, Yale University, New Haven, CT.
Lyra, P., Roazzi, A., \& Garvey, A. (2008). Emergência da teoria da mente em relações sociais. Em T. M. Sperb \& M. R. Maluf (Org), Desenvolvimento sociocognitivo: Estudos brasileiros sobre teoria da mente (pp. 55-92). São Paulo: Vetor.

Maluf, M. R., \& Domingues, S. (2010). Teoria da mente e linguagem: Importância e contribuições dos estudos de intervenção. Em M. C. Rodrigues \& T. M. Sperb (Org.), Contextos de desenvolvimento da linguagem (pp.137-158) São Paulo: Vetor.

Maluf, M. R., \& Gallo-Pena, E. C. (2011). Atribuição de estados mentais e compreensão conversacional: Estudo com préescolares. Paideia, 21, 45-50.

Nelson, K. (2005). Language pathways into the community of minds. Em J. Astington \& J. Baird (Eds.), Why language matters for theory of mind (pp. 27-49). New York: Oxford University Press.

Nelson, K. (2006). Construction of the cultural self in early narratives. Em C. Daiute \& C. Lightfoot (Org), Narrative Analysis: Studying the development of individuals in society. (pp. 87-109). Thousand Oaks, CA: SAGE Publications.

Panciera, S. D. P. (2007). Linguagem e desenvolvimento da Teoria da Mente: Um estudo com crianças de 3 a 5 anos (Tese de Doutorado não publicada). Curso de Pós-Graduação em Psicologia, Universidade de São Paulo, São Paulo (Brasil) e Departamento de Psicologia do Desenvolvimento, Université de Rennes 2, Rennes, França.

Premack, D. \& Woodruff, G. (1978). Does the chimpanzee have a theory of mind? Behavioral and Brain Sciences, 1, 515-526.

Piaget, J. (1961). A linguagem e o pensamento da criança. Rio de Janeiro: Editora Fundo de Cultura. (Original publicado em 1923)

Rodrigues, M. C., \& Pires, L. (2010). Teoria da mente: linguagem e contextos de desenvolvimento infantil. Em M. C. Rodrigues \& T. M. Sperb (Org.), Contextos de desenvolvimento da linguagem (pp.137-158) São Paulo: Vetor.

Rodrigues, M., Pelisson, M., Silveira, F. Ribeiro, N., \& Silva, R. (2015). Avaliação da teoria da mente: estudo com alunos de escolas públicas e particulares. Estudos de Psicologia, 32, 213-220.

Rosnay, M., Pons, F., Harris, P. L., \& Morrell, J. M. B. (2004). A lag between understanding false belief and emotion attribution in young children: Relationships with linguistic ability and mothers' mental-state language. British Journal of Developmental Psychology, 22, $197-218$.

Ruffman, T., Slade, L., \& Crowe, E. (2002). The relation between child and mothers' mental state language and theory-of-mind understanding. Child Development, 73, 734-751.

Salkind, N. J. (1997). Exploring research. New Jersey, NJ: Upper Saddle River.

Slaughter, V., Peterson, C., \& Mackintosh, E. (2007). Mind what mother says: Narrative input and theory of mind in typical children and those on the autism spectrum. Child Development, $78(3), 839-858$. 
Souza, D.B. (2008). De onde e para onde? As interfaces entre linguagem, teoria da mente e desenvolvimento social. Em T. M. Sperb \& M. R. Maluf(Org), Desenvolvimento sociocognitivo: Estudos brasileiros sobre teoria da mente (pp. 33-54). São Paulo: Vetor.

Symons, D., Peterson, C., Slaughter, V., Roche, J., \& Doyle, E. (2005). Theory of mind and mental state discourse during book reading and story-telling tasks. British Journal of Developmental Psychology, 23, 1-24.
Taumoepeau, M., \& Ruffman, T. (2006). Mother and infant talk about mental states relates to desire language and emotion understanding. Child Development, 77(2), 465-481.

Wimmer, H., \& Perner, J. (1983). Beliefs about beliefs: Representation and constraining function of wrong beliefs in young children's understanding of deception. Cognition, 13, 103-128. 